\title{
V UG-So-07 NUEVA VARIEDAD DE SOYA PARA LA COSTA ECUATORIANA
}

\section{UG-So-07 NEW SOYBEAN VARIETY TO THE ECUADORIAN COAST}

\author{
Vicente Painii-Montero^, Olimpa Santillán-Muñóz ${ }^{2}$ y Felipe R. Garcés-Fiallos ${ }^{3}$
}

\footnotetext{
'Universidad de Guayaquil, Facultad de Ciencias para el Desarrollo, Palestina, Ecuador. ${ }^{2}$ Asociación de Productores Orgánicos de Vinces, Palestina, Ecuador. ${ }^{3}$ Universidad Técnica de Manabí, Facultad de Agronomía, Campus Experimental La Teodomira, Portoviejo, Manabí, Ecuador.

*Autor para correspondencia (vicente.painiim@ug.edu.ec)
}

La producción de soya [Glycine max (L) Merril.] en el Ecuador se inició en el año 1973 con la siembra de 1227 ha. En la zona centro del sur de la región costa, cuatro de cada 10 agricultores se dedican al cultivo de soya (Moreno y Salvador, 2015). A pesar de que en el país existen variedades mejoradas de soya, el rendimiento nacional promedio en el año 2015 (2040 kg ha-1) fue inferior al de países vecinos (Garcés-Fiallos et al., 2014). Actualmente las variedades recomendadas son INIAP-308 y P-34. La variedad V UG-So-07, generada en la Facultad de Ciencias para el Desarrollo (FACDE) de la Universidad de Guayaquil (UG), es una nueva opción para los productores de soya de la zona centro del sur del litoral ecuatoriano, donde el cultivo se siembra en condiciones de secano.

En Ecuador, el Servicio Nacional de Derechos Intelectuales (SENADI) concede la protección de una nueva variedad vegetal, siempre y cuando cumpla con los requisitos de distinción, homogeneidad y estabilidad (UPOV, 2002), como es el caso de la variedad V UG-So-07. El proceso de mejoramiento genético de esta variedad comenzó en el año 2006, a partir del cruzamiento entre los genotipos Vinces UG-2 y Vinces UG-3, que provenían de las líneas avanzadas Br-85-610 y Totai, respectivamente.
A partir de la generación $F_{2}$ se efectuó selección individual en generaciones segregantes sucesivas (método de pedigrí o genealógico), hasta la $\mathrm{F}_{7}$ en el año 2014. En este proceso V UG-So-07 (pedigrí VUG-3 × UG2 67-9-7) se seleccionó con base en su arquitectura de planta, altura de carga (distancia del suelo a las primeras vainas), tolerancia a la roya asiática (Phakopsora pachyrhizi) y potencial productivo.

Durante los años 2015, 2016 y 2017 esta variedad se evaluó en experimentos de campo que se establecieron en las localidades de Vinces y Puebloviejo, ambas zonas representativas del cultivo de soya en la costa ecuatoriana. El rendimiento medio de V UG-So-07 superó en 19 y 49 \% a las variedades testigo INIAP-308 y P-34, respectivamente (Cuadro 1). La floración de esta nueva variedad (47 días) es más tardía que INIAP-308 (43 días) y P-34 (39 días). Su altura media $(92 \mathrm{~cm})$ es intermedia entre INIAP-308 (68 $\mathrm{cm})$ y P-34 $(111 \mathrm{~cm})$. El número de semillas por vaina $(2.76)$ de esta variedad es mayor al de P-34 (2.15), pero similar al de INIAP-308 (2.46); finalmente, la altura de carga (23.50 $\mathrm{cm})$ de V UG-So-07 supera a INIAP-308 $(11.73 \mathrm{~cm})$ y P-34 $(12.16 \mathrm{~cm})$.

Cuadro 1. Rendimiento promedio $\left(\mathrm{kg} \mathrm{ha}^{-1}\right)$ de la nueva variedad V UG-So-07 y de los testigos INIAP-308 y P-34 en seis ambientes en los años 2015, 2016 y 2017. Provincia de Los Ríos, Ecuador.

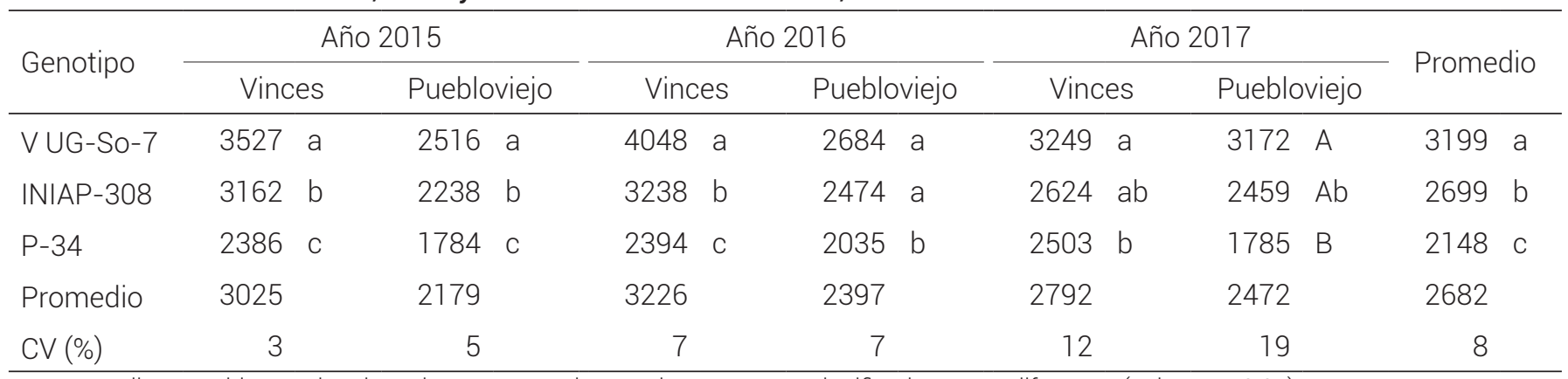

Los promedios seguidos por la misma letra en una misma columna no son significativamente diferentes (Tukey, P $\leq 0.05$ ) 


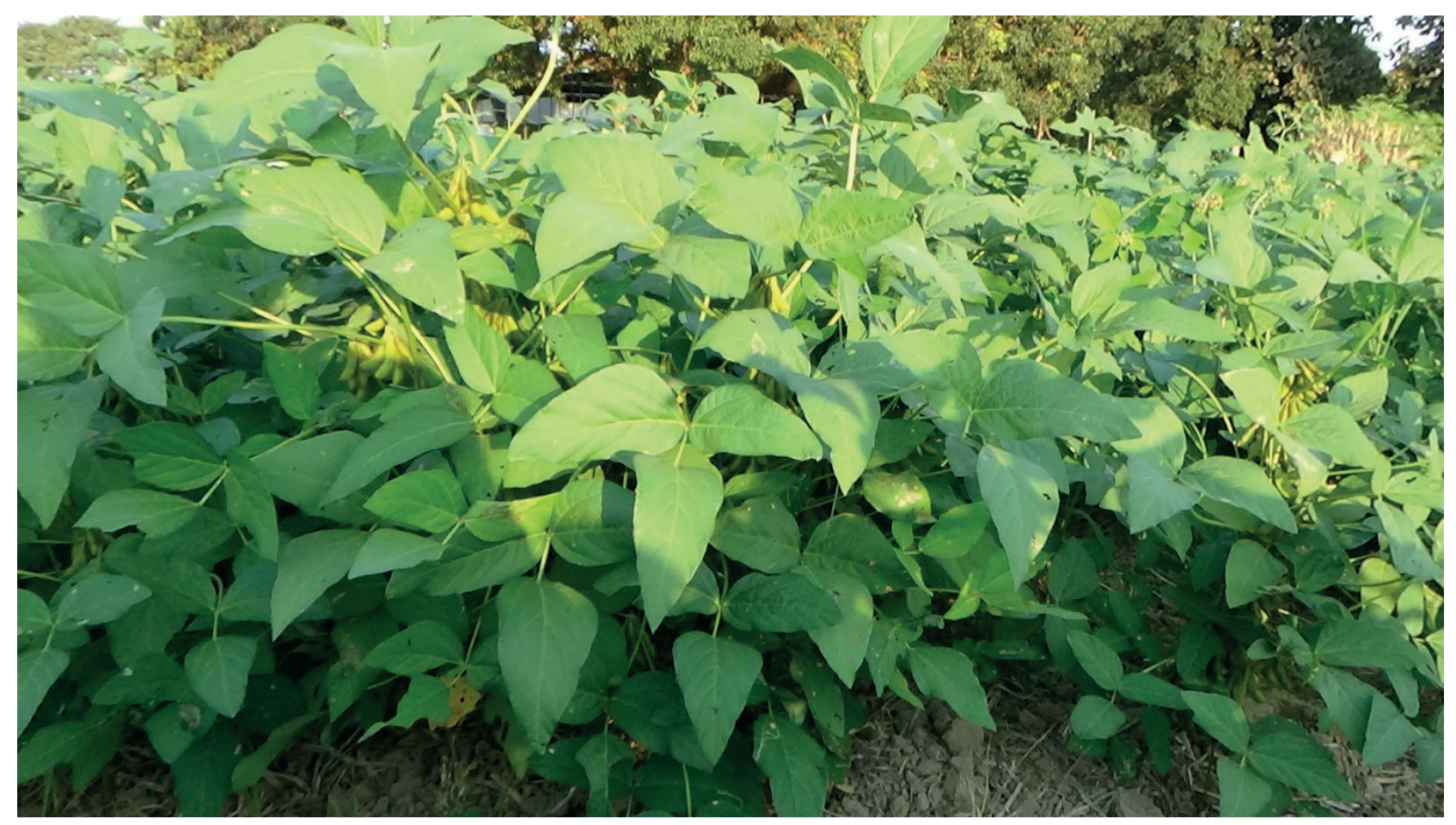

Figura 1. Variedad V UG-So-07 en condiciones de secano durante su estado fenológico R6 (llenado de grano).

En cuanto a las características morfológicas referidas en los descriptores varietales de la Unión Internacional para la Protección de las Obtenciones Vegetales (UPOV, 2002) destacan las siguientes: ausencia de pigmentación antociánica del hipocótilo, hábito de crecimiento determinado, porte semierecto de planta, vellosidad del tallo principal de color castaño, altura de la planta entre media y alta, altura de carga alta, inicio de floración tardía, abullonado débil de hojas, folíolo lateral con formato oval puntiagudo, hoja de tamaño mediano, folíolo lateral color verde y de intensidad media, flor de color blanco, vaina color marrón con grado medio de intensidad, semilla de tamaño grande y de forma subesférica, tegumento con el fondo de color amarillo y tolerancia a Phakopsora pachyrhizi (Figura 1).

Desde el punto de vista agronómico, V UG-So-07 es una variedad con un porte semierecto, su altura de planta es media a alta, semilla grande, floración tardía, lo cual es deseable debido al fotoperiodo de la región (Hinson et al., 1982). La madurez se ubica entre media y tardía, la cantidad de semillas por vaina es alta, con una altura de carga superior a $13 \mathrm{~cm}$, ideal para cosecha mecanizada (Fajardo, 2015; Com. Pers.)'

'Fajardo G. J. F. (2015) Comportamiento agronómico de dos líneas de soya (Glycine max L.) con tres densidades poblacionales en la zona de Quevedo, provincia de Los Ríos, 2013. Tesis de Grado. Universidad Técnica Estatal de Quevedo. Quevedo, Ecuador.
Esta variedad presenta un rendimiento de $3199 \mathrm{~kg} \mathrm{ha}^{-1}$, superior al resto de genotipos evaluados (Cuadro 1), así como a otras variedades como Kamerún (2696 kg ha-1), sembrada en condiciones semejantes en el Ecuador (Garcés-Fiallos et al., 2014).

Mediante resolución No. 027-2018-DNOV-SENADI del 13 de junio de 2018, se autorizó el registro e inscripción del cultivar V UG-So-07 en el Registro Nacional de Variedades Vegetales Protegidas, así como otorgar el Certificado de Obtentor No. 18-952. La semilla de categoría básica está disponible en el Programa de Mejoramiento de la Universidad de Guayaquil, previo convenio interinstitucional.

\section{BIBLIOGRAFÍA}

Garcés-Fiallos F. R., S. A. Ampuño-Muñoz y G. H. Vásconez-Montúfar (2014) Agronomía, producción y calidad de grano de variedades de soya durante dos épocas de cultivo. Bioscience Journal 30:717-729.

Hinson K., E. E. Hartwig and H. C. Minor (1982) Soybean Production in the Tropics. FAO Plant Production and Protección Paper. Food and Agriculture Organization. Rome. Italy. 222 p.

Moreno A. B. y S. Salvador S. (2015) Rendimientos y características de soya en el Ecuador verano 2015. Sistemas de Información, Ministerio de Agricultura y Ganadería. Quito, Ecuador. https:// studylib.es/doc/5096623/rendimientos-y-caracteristicas-desoya-en-el (Diciembre 2016).

UPOV, Unión Internacional para la Protección de las Obtenciones Vegetales (2002) Introducción general al examen de la distinción, la homogeneidad, estabilidad y la elaboración de descripciones armonizadas de las obtenciones vegetales. TG/1/3. Unión Internacional para la Protección de las Obtenciones Vegetales. Ginebra, Suiza. 28 p. 